\begin{tabular}{|} 
Ambiente \& Água - An Interdisciplinary Journal of Applied Science \\
ISSN 1980-993X - doi:10.4136/1980-993X \\
www.ambi-agua.net \\
E-mail: ambi-agua@agro.unitau.br
\end{tabular}

\title{
Modelagem neural e análise estatística do processo de degradação de chorume por foto-Fenton solar
}

\author{
doi: 10.4136/ambi-agua.1341
}

Received: 13 Mar. 2014; Accepted: 19 Nov. 2014

\author{
Alessandro Sampaio Cavalcanti ${ }^{1 *}$; Hélcio José Izário Filho; \\ Oswaldo Luiz Cobra Guimarães ${ }^{2}$; Adriano Francisco Siqueira ${ }^{2}$ \\ Universidade de São Paulo (EEL-USP), Lorena, SP, Brasil \\ ${ }^{1}$ Departamento de Química \\ ${ }^{2}$ Departamento de Ciências Básicas e Ambientais \\ *Autor correspondente: e-mail: alessandro@dequi.eel.usp.br, \\ oswaldocobra@debas.eel.usp.br, helcio@dequi.eel.usp.br, \\ adriano@debas.eel.usp.br
}

\section{RESUMO}

O chorume em estudo é oriundo da cidade de Cachoeira Paulista-SP, apresentando baixa biodegradabilidade, devendo ser pré-tratado por um processo oxidativo. O objetivo desse trabalho foi obter um modelo neural em conjunto com análises estatísticas que representassem a degradação do chorume in natura pelo processo foto-Fenton solar, em função da redução da demanda química de oxigênio (DQO). Redes neurais apresentam-se como uma alternativa para a modelagem de processos não-lineares como os processos oxidativos avançados, que envolvem um grande número de variáveis de controle e complexas reações envolvidas. O processo fotocatalítico foi otimizado por um planejamento fatorial fracionado $\left(2^{4-1}\right)$ em duplicata e triplicata no ponto central, sendo as variáveis de entrada em três níveis: $\mathrm{pH}$, radiação solar e concentrações de $\mathrm{H}_{2} \mathrm{O}_{2}$ e $\mathrm{Fe}^{2+}$. $\mathrm{O}$ sistema de tratamento em escala de bancada utilizou um reator batelada, com volume constante $(3 \mathrm{~L})$ de chorume, vazão $13 \mathrm{~L} \mathrm{~min}^{-1}$ e 2-h de reação. A otimização do processo mostrou que o efeito individual de cada variável de entrada deve operar em seu maior nível, sendo que a variável $\mathrm{Fe}^{2+}$ teve significância na forma combinada. A redução percentual de DQO do melhor experimento foi de $88,7 \%$, sendo esta avaliada em um custo de $\mathrm{R} \$ 126,67 \mathrm{~m}^{-3}$ de chorume. O processo de degradação foi modelado via redes neurais feedforward backpropagation, com coeficientes de correlação linear para os conjuntos de treinamento, validação e teste acima de 0,9 , indicando alta predição e generalização do modelo neural proposto. A rede neural proposta mapeou um espaço multidimensional da forma $\triangle D Q O=f\left(t, p H,\left[\mathrm{H}_{2} \mathrm{O}_{2}\right], P_{U V},\left[\mathrm{Fe}^{2+}\right]\right)$.

Palavras-chave: aterro sanitário, análise econômica, processo oxidativo avançado.

\section{Neural modeling and statistical analysis of the degradation process of leachate by the solar photo-Fenton process}

\section{ABSTRACT}

This study sought to obtain a neural model and statistical analyzes that represented the degradation of leachate in natura by the solar photo-Fenton process, according to the 
reduction of chemical oxygen demand (COD). The study used leachate from the town of Cachoeira Paulista-SP, which had low biodegradability and required pre-treatment by an oxidative process. Neural networks are presented as an alternative for the modeling of nonlinear processes such as advanced oxidation processes, which involve a large number of control variables and complex reactions. The photo-catalytic process was optimized by a fractional $\left(2^{4-1}\right)$ factorial design in duplicate and triplicate, with the center point being the input variables at three levels: $\mathrm{pH}$, solar radiation and concentrations of $\mathrm{H}_{2} \mathrm{O}_{2}$ and $\mathrm{Fe}^{2+}$. The treatment system used an open reactor in bench scale with a constant volume $(3 \mathrm{~L})$ of leachate flow of $13 \mathrm{~L} \mathrm{~min}^{-1}$ and a 2 -h reaction. The optimization process showed that the individual effect of each input variable should operate at its highest level, and that the variable $\mathrm{Fe}^{2+}$ was significant for the combination. The percentage reduction of COD of the best experiment was $88.7 \%$, which is valued at a cost of $\mathrm{R} \$ 126.67 \mathrm{~m}^{-3}$. The degradation process was modeled via feedforward backpropagation neural networks with linear correlation coefficients for the training sets, validation and test above 0.9 , indicating high prediction and generalization of the proposed neural model. The proposed neural network mapped a multidimensional space of the form $\triangle D Q O=f\left(t, p H,\left[\mathrm{H}_{2} \mathrm{O}_{2}\right], P_{U V},\left[\mathrm{Fe}^{2+}\right]\right)$.

Keywords: advanced oxidation, economic analysis, landfill.

\section{INTRODUÇÃO}

\subsection{Processo foto-Fenton}

Um dos grandes problemas encontrados pela sociedade moderna é resolver a questão do lixo urbano e seu consequente depósito no ambiente. O destino impróprio dos resíduos sólidos, em áreas que não possuem uma infraestrutura adequada para o controle dos poluentes, poderá causar uma degradação ambiental (poluição do solo, do ar, das águas superficiais e subterrâneas, proliferação de vetores, contaminação da biota e desequilíbrio ecológico), acarretando riscos à saúde humana. E esse problema vem sendo discutido nos mais variados recursos midiáticos, pois são sentidas diretamente na qualidade do ar, das águas superficiais e subterrâneas e dos solos (Vilela-Ribeiro et al., 2009).

A fração líquida, conhecida como chorume ou lixiviado, é originada pela umidade natural presente nos resíduos, pelo processo de decomposição da matéria orgânica e pelas águas das chuvas percoladas sobre a massa de resíduo, onde várias substâncias orgânicas e inorgânicas são arrastadas e farão parte da composição do chorume, que é um líquido escuro e apresenta um sério problema ambiental, devido ao seu alto potencial de contaminação. Os resíduos sólidos dispostos nos lixões ou nos aterros sofrem os processos de decomposição física, química e biológica, dando origem a efluentes líquidos e gasosos (Kjeldsen et al., 2002).

A complexidade da composição do lixiviado gera grandes dúvidas na técnica de seu tratamento; no caso dos lixiviados novos ( $<2$ anos), onde predomina alta biodegradabilidade, ou seja alta razão de Demanda Química de Oxigênio em relação a Demanda Bioquímica de Oxigênio $\left(\mathrm{DBO}_{5} / \mathrm{DQO}>0,6\right)$, o processo biológico tem sido recomendado. Entretanto, para os lixiviados maduros ( $>10$ anos), onde predominam a baixa biodegradabilidade $\left(\mathrm{DBO}_{5} / \mathrm{DQO}<0,2\right)$, é constituída de substâncias refratárias e com alto peso molecular (húmicas e fúlvicas), que dificultam o processo biológico (Zhang et al., 2005).

A característica físico-química do lixiviado é influenciada por alguns fatores, como: variações climáticas, técnica de aterramento e método de compactação, os quais influenciam na quantidade e na qualidade do lixiviado produzido no aterro. $\mathrm{O}$ seu envelhecimento é caracterizado pela presença de substâncias recalcitrantes (Telles, 2010).

Justifica-se o estudo de diferentes processos oxidativos avançados no tratamento do lixiviado por se tratar de uma mistura complexa, sendo muitas vezes, necessário o emprego de 
duas ou mais tecnologias de tratamento para se obter um lixiviado dentro dos padrões para descarte (Telles, 2010).

A oxidação de compostos orgânicos sob irradiação UV na presença de íon de ferro, em meio ácido, foi verificada nas décadas anteriores, quando foi postulado que a transferência eletrônica iniciada pela irradiação resultava na geração de $\bullet \mathrm{OH}$, responsável pelas reações de oxidação. Com o aumento do $\mathrm{pH}$, ocorre hidrólise formando espécies hidroxiladas, como mostra a Equação 1.

$$
\mathrm{Fe}^{3+}+\mathrm{H}_{2} \mathrm{O} \rightarrow \mathrm{Fe}(\mathrm{OH})^{2+}+\mathrm{H}^{+}
$$

Quando complexos de Fe (III) são irradiados, ocorre a promoção de um elétron de um orbital centrado no ligante para um orbital centrado no metal, chamada de transferência de carga ligante-metal ("ligand to metal charge transfer", LMCT), que implica na redução de $\mathrm{Fe}(\mathrm{III})$ a $\mathrm{Fe}(\mathrm{II})$ e oxidação do ligante (Equação 2), formando o radical hidroxila (Nogueira et al., 2007).

$$
\mathrm{Fe}(\mathrm{OH})^{2+}+h v \rightarrow \mathrm{Fe}^{2+}+\cdot \mathrm{OH}
$$

$\mathrm{O} \mathrm{Fe}^{2+}$ gerado durante a irradiação da luz solar, quando na presença de peróxido de hidrogênio $\left(\mathrm{H}_{2} \mathrm{O}_{2}\right)$, reage com este dando seqüência à reação de Fenton (Equação 3). Assim, a reação é catalítica e é estabelecido um ciclo em que $\mathrm{Fe}^{2+}$ (íon ferroso) é regenerado. Otimizado o custo de reagente e aliado à irradiação solar, abundante e intensa na região Sudeste, onde se desenvolveu esse projeto, o processo oxidativo pode ser viabilizado economicamente (Vilar et al., 2011).

$$
\mathrm{Fe}^{2+}+\mathrm{H}_{2} \mathrm{O}_{2} \rightarrow \mathrm{Fe}^{3+}+\mathrm{HO}^{-}+\cdot \mathrm{OH}
$$

Neste contexto, este trabalho tem como objetivo obter um modelo neural que represente a degradação do chorume in natura em função da redução de DQO, utilizando-se o processo foto-Fenton solar, além de analisar estatisticamente os resultados obtidos do processo de degradação.

\subsection{Redes Neurais}

As Redes neurais artificiais (RNA) podem ser definidas como sendo sistemas paralelos distribuídos, compostos por unidades de processamento simples que computam determinadas funções matemáticas (normalmente não-lineares). Tais unidades são dispostas em uma ou mais camadas e interligadas por um grande número de conexões, geralmente unidirecionais (Haykin, 1999).

Cerqueira et al. (2001) definem redes neurais "como um conjunto de métodos matemáticos e algoritmos computacionais, especialmente projetados para simular o processamento de informações e aquisição de conhecimento do cérebro humano". Os autores observam que se pode considerar uma rede neural como uma "caixa de processamento", que pode ser treinada para que, a partir de um conjunto de entradas (input), o mesmo forneça um conjunto de saída (output).

Uma rede neuronal é um processador distribuído massivamente em paralelo, que tem a propensão natural para armazenar conhecimentos experimentais e torná-los disponíveis para uso. Em uma rede neural conhecimento é adquirido pela rede através do processo de aprendizagem, e os pesos das conexões entre neurônios, conhecido como sinapses, são usados para armazenar o conhecimento (Haykin, 1999). 
As RNA possuem a característica de serem consideradas como aproximadores universais de funções, podendo realizar em mapeamento de um espaço vetorial em outro espaço vetorial (Svozil et al., 1997).

De forma geral, uma rede neural artificial pode ser vista como uma estrutura interconectada formada por uma camada de neurônios de entrada, um número de camadas ocultas e uma camada de saída. Fundamentalmente, redes neurais são aproximadores universais de funções com poder de classificação, associação e predições.

A função de transferência é necessária para a transformação da soma dos pesos ponderados dos sinais de entrada nos neurônios, de forma a determinar o valor ou intensidade do sinal de saída. As funções de transferência, também chamadas funções de ativação, limitam a amplitude do intervalo do sinal de saída do neurônio para algum valor finito, geralmente num intervalo normalizado.

Elmolla et al. (2010) realçam a dificuldade de modelamento matemático devido à complexidade química dos processos oxidativos avançados e, desta forma, redes neurais podem ser utilizadas na modelagem matemática do processo de degradação de efluentes, em função de sua simplicidade de simulação, predição e modelagem. As vantagens da modelagem neural envolvem o fato de que a descrição do fenômeno de degradação não é necessária e tempo menor é requerido para o desenvolvimento do modelo, comparados aos modelos matemáticos tradicionais. Neste sentido, Guimarães et al. (2008) utilizaram uma rede neural feedforward backpropagation para predição do ponto crítico de adição de peróxido de hidrogênio, no processo de descoloração de azo corantes através da utilização de $\mathrm{UV} / \mathrm{H}_{2} \mathrm{O}_{2}$.

$\mathrm{Na}$ maioria dos modelos, estas conexões estão associadas a pesos que armazenam o conhecimento representado no modelo, e servem para ponderar a entrada recebida por cada neurônio da rede. A solução de problemas com RNA passa inicialmente por uma fase de aprendizagem, onde um conjunto de exemplos é apresentado para a rede, que extrai automaticamente as características necessárias para representar a informação fornecida. Essas características são utilizadas posteriormente para gerar respostas para o problema.

Kato et al. (2001) aplicaram a técnica de redes neurais com algoritmo de correção de pesos do tipo backpropagation, na predição de DQO de efluentes sintéticos contendo fenol, ácido salicílico, anilina e lignina. Estes efluentes continham substâncias que poderiam influir no processo de determinação de DQO. Espécies inorgânicas como halogênios e sulfato ferroso possuem caráter redutor para o dicromato de potássio usado na determinação da DQO, interferindo no resultado de análise. Na etapa de validação, os autores alcançaram um erro médio de 12,67 \% para amostras contendo interferentes inorgânicos. A presença destes interferentes reveste o processo de medição de DQO de não linearidades.

Os modelos do tipo entrada-saída são úteis na representação matemática de processos complexos, para os quais o desenvolvimento de modelos fenomenológicos seria uma tarefa complexa e potencialmente revestida de consumo de tempo e investimento financeiro apreciável.

Diversos estudos indicam a potencialidade de aplicação de redes neurais, independente de sua arquitetura (como por exemplo redes feedfoward ou Mapas de Kohonen), em processos de tratamento de efluentes, sendo indiferente ao método de mineralização utilizado, sejam eles processos oxidativos ou biológicos. Çinar (2005) utilizou uma rede do tipo Mapas de Auto-Organização de Kohonen, para classificar dados de operação de tratamento de plantas de Pelham e determinar as razões para as altas concentrações de demanda bioquímica de oxigênio (DBO), sólidos suspensos totais (SST) e coliformes fecais neste estudo. A rede de Kohonen é uma rede neural não supervisionada que pode ser utilizada para reduzir a quantidade de dados por clusterização e projetar a não-linearidade dos dados em um espaço dimensional de menor ordem. No trabalho, dados operacionais de 400 dias foram utilizados para alimentar a rede e clusterizar o conjunto amostral, indicando altos valores de parâmetros 
de demanda bioquímica de oxigênio (DBO), TSS e coliformes fecais. Os autores consideram que o uso da rede de Kohonen à avaliação de plantas de tratamento de efluentes é uma maneira eficiente de determinar as complexas dependências das variáveis de processo e, desta forma, resolver problemas operacionais em plantas de tratamento de efluentes.

Em relação à aplicação de redes neurais na modelagem de processos oxidativos avançados, também pode ser citado o trabalho de Pareek et al. (2002), no qual ocorreu a modelagem da fotodegradação do denominado "Bayer liquor", pela catálise do dióxido de titânio. Neste trabalho, os autores modelaram a razão de reação com coeficientes de correlação acima de 0.99, e estudaram a influência dos parâmetros de entrada pela utilização da partição dos pesos de conexão de Garson. A rede neural proposta pelos autores seguiu uma arquitetura feedforward, com uma camada oculta.

Algumas características do processo foto-Fenton indicam as vantagens da utilização de redes neurais em seu processo de modelagem. Os radicais hidroxila formados reagem com espécies orgânicas, e o mecanismo que envolve o processo foto-Fenton é formado por inúmeras reações elementares com diversos radicais e formação de complexos de ferro com água, além de espécies intermediárias e diversos interferentes. Realça-se a complexidade das matrizes químicas de percolados de aterro sanitário. Desta forma, mecanismo de degradação de efluentes orgânicos não obedecem a uma ordem de reação definida (Nadtochenco e Kiwi, 1998; Wang e Lemley, 2001; Giroto, 2002).

Giroto (2002) relata que a complexidade do mecanismo fotoquímico induz a grandes dificuldades na determinação de modelos cinéticos. O radical hidroxila é não seletivo, dificultando a descrição por modelos cinéticos de forma simples.

Giordani (2003) salienta a capacidade de trabalho das redes neurais com fenômenos não lineares, e que esta capacidade é uma poderosa ferramenta para a indústria de processos químicos, onde a não-linearidade é quase constante, sendo que na rede neural as não-linearidades são introduzidas pelas funções de transferência.

No presente trabalho, a rede neural utilizada foi uma rede do tipo feedforward, contendo três camadas (entrada, oculta e de saída).

$\mathrm{O}$ critério de ajuste da rede neural feedforward usando o algoritmo bach-propagation foi a minimização do erro quadrático médio para os conjuntos de treinamento, validação e teste.

O comportamento funcional da rede feedforward (Hamed et al., 2004) pode ser definido conforme Equação 4.

$$
\bar{Y}_{i}=f_{o}\left[\sum_{j=1}^{h_{n}} W_{o_{j}} * f_{h}\left(\sum_{i=1}^{m} W H_{i j} \cdot X_{i}+b_{j}\right)+b_{o}\right]
$$

$\mathrm{Na}$ Equação 4, $\mathrm{WH}_{\mathrm{ij}}$ representa os pesos entre a j-ésima entrada e a j-ésimo neurônio oculto, m é o número de neurônios de entrada, Woj representa os pesos entre o j-ésimo neurônio oculto e o neurônio de saída, $\mathrm{f}_{\mathrm{h}}$ representa a função de ativação do neurônio oculto e $f_{o}$ a função de ativação do neurônio de saída, $b_{j}$ representa a bias do j-ésimo neurônio oculto, $b_{o}$ a bias do neurônio de saída e $h_{n}$ é o número de neurônios ocultos. Nesta notação, fica explícito o caráter funcional da modelagem neural. Desta forma, $y_{i}$ pode representar um valor de predição, no sentido funcional ou de classificação.

O objetivo básico da modelagem neural é a minimização de uma função erro. Neste desenvolvimento, a função Erro Quadrático Médio é representada pela (Equação 5), em que N representa o número de amostras do experimento.

$$
M S E=\sum_{i=1}^{N}\left(Y_{i}-\bar{Y}_{i}\right)^{2} / N
$$




\section{MATERIAL E MÉTODOS}

A descrição de Materiais e Métodos foi subdivida em 4 subseções de forma a um melhor entendimento dos processos de caracterização analítica, experimental e modelagem neural.

\subsection{Amostragem e preservação}

O chorume utilizado nos experimentos foi proveniente do aterro sanitário da cidade de Cachoeira Paulista localizado na Estrada Municipal de Fiuta, km 4 - Bairro do Jardim no interior de São Paulo, região do vale do Paraíba, Brasil. O aterro sanitário está em operação desde o ano de 2006 e recebe um volume médio de lixo de 100 ton $\mathrm{dia}^{-1}$.

A coleta do chorume foi realizada na caixa de mistura (tipo tanque equalizador), antes deste entrar na lagoa de estabilização. Foram coletados $80 \mathrm{~L}$ de chorume em um dia ensolarado e seco numa temperatura de $23{ }^{\circ} \mathrm{C}$, em agosto de 2011 . O mesmo foi homogeneizado e acondicionado em uma câmara fria a $4{ }^{\circ} \mathrm{C}$ do LOT (Departamento de Biotecnologia) da EEL-USP, para minimizar possíveis alterações das propriedades físicoquímicas (APHA et al., 1999).

\subsection{Metodologias analíticas}

As metodologias utilizadas para as caracterizações analíticas do chorume in natura e após tratamentos oxidativos foram adaptadas segundo Standard Methods (APHA et al., 1999). As determinações de DQO foram realizadas com digestão em tubo fechado, seguida de determinação espectrofotométrica (espectrofotômetro SP 1105) em $620 \mathrm{~nm}$. As determinações de $\mathrm{DBO}_{5}$ (Demanda Bioquímica de Oxigênio 5 dias) foram incubadas (SP 500) por um período de 5 dias com inoculação de microorganismos tipo Seed, a $20 \pm 3{ }^{\circ} \mathrm{C}$, onde a medida de oxigênio, antes e após a incubação, foi feita pelo método titrimétrico de Winkler modificado pela azida sódica (Lima et al., 2006). As análises de sólidos seguiram procedimento gravimétrico clássico, em cápsulas de porcelana com massas previamente estabilizadas. $\mathrm{O}$ processo de secagem, a $105^{\circ} \mathrm{C}$, foi realizado em estufa (SP LABOR) e o processo de calcinação, a $650{ }^{\circ} \mathrm{C}$, foi realizado em um forno tipo mufla (SP LABOR). As pesagens foram feitas em balança analítica marca SHIMADZU, modelo AY 220. As análises de Nitrogênio Amoniacal e Orgânico utilizaram a prévia destilação para sua posterior determinação espectrofotométrica. A concentração de óleo e graxa foi determinada pelo método de extração por solvente (hexano) em um sistema de Soxhlet, sendo previamente adsorvido em diatomácea, em meio ácido clorídrico. Fosfato, após digestão ácida para a forma solúvel, e cloreto foram determinadas por métodos espectrofotométricos. As determinações de carbono orgânico foram realizadas em um analisador de carbono orgânico total da Shimadzu, modelo TOC-VCPH, fundamentado na oxidação catalítica a elevadas temperaturas e determinação de $\mathrm{CO}_{2}$ por espectroscopia no infravermelho. Para determinação do carbono orgânico, a curva de calibração foi preparada a partir de um padrão de biftalato de potássio, na faixa linear de $0-1000 \mathrm{mg} \mathrm{L}^{-1}$. As determinações analíticas dos elementos metálicos nas amostras, previamente digeridas em meio ácido e em sistema fechado, foram realizadas em um espectrômetro de absorção atômica, marca PerkinElmer, modelo Aanalyst 800. Para a determinação do peróxido de hidrogênio residual foi utilizado o método espectrofotométrico, com o reagente complexante metavanadato de amônio. A concentração de peróxido de hidrogênio foi monitorada pela formação de um complexo com absorvidade em $450 \mathrm{~nm}$, pela reação de $\mathrm{H}_{2} \mathrm{O}_{2}$ com metavanadato de amônio $\left(\mathrm{NH}_{4} \mathrm{VO}_{3}\right)$ (Guimarães et al., 2007).

\subsection{Procedimento experimental}

Os experimentos foram realizados em um reator semi-batelada aberto para a absorção das radiações UV solar, conforme mostra a Figura 1, constituído basicamente de uma bomba 
centrífuga (BOMAX, Modelo NH-30PX-T e vazão de $13 \mathrm{~L} \mathrm{~min}^{-1}$ ), um reservatório cilíndrico $(19,9 \mathrm{~cm}$ x 23,9 cm) e uma placa metálica $(25 \mathrm{~cm}$ de largura e $75 \mathrm{~cm}$ de comprimento, com uma área útil de $1875 \mathrm{~cm}^{2}$ ), sem pigmentação denominada branco. $\mathrm{O}$ controle e ajuste do $\mathrm{pH}$ durante os experimentos foram realizados no reservatório, com um pHmetro (PH21 pH/mV HANNA) e a intensidade da radiação solar foi medida através de um radiômetro portátil (IL 1430 UV Health Hazard - Actinic). No sistema fotocatalítico, o chorume era bombeado até a parte superior da placa, na qual era distribuído por toda a placa, através de um tubo de PVC perfurado, que por gravidade percolava por toda a extensão da placa, sob uma fina e uniforme camada, enquanto recebia a radiação solar. Esta foi colocada sobre um suporte de madeira em sentido ao equador, com um ângulo de inclinação de $23^{\circ}$ (aproveitamento melhor a incidência da radiação na fotocatálise). Concomitantemente, o volume do reagente de $\mathrm{FeSO}_{4} \cdot 7 \mathrm{H}_{2} \mathrm{O}\left(0,82 \mathrm{~mol} \mathrm{~L}^{-1}\right)$ foi adicionado totalmente no início da reação e $\mathrm{o}_{2} \mathrm{O}_{2}\left(30 \% \mathrm{~m} \mathrm{~m}^{-1}\right)$ durante $60 \mathrm{~min}$ do tempo total de 2-h. Durante a reação fotocatalítica utilizou-se $\mathrm{NaOH}$ e $\mathrm{H}_{2} \mathrm{SO}_{4}$ (ambos a $5 \mathrm{eq} \mathrm{L}^{-1}$ ) para ajustar e controlar o $\mathrm{pH}$ do processo.

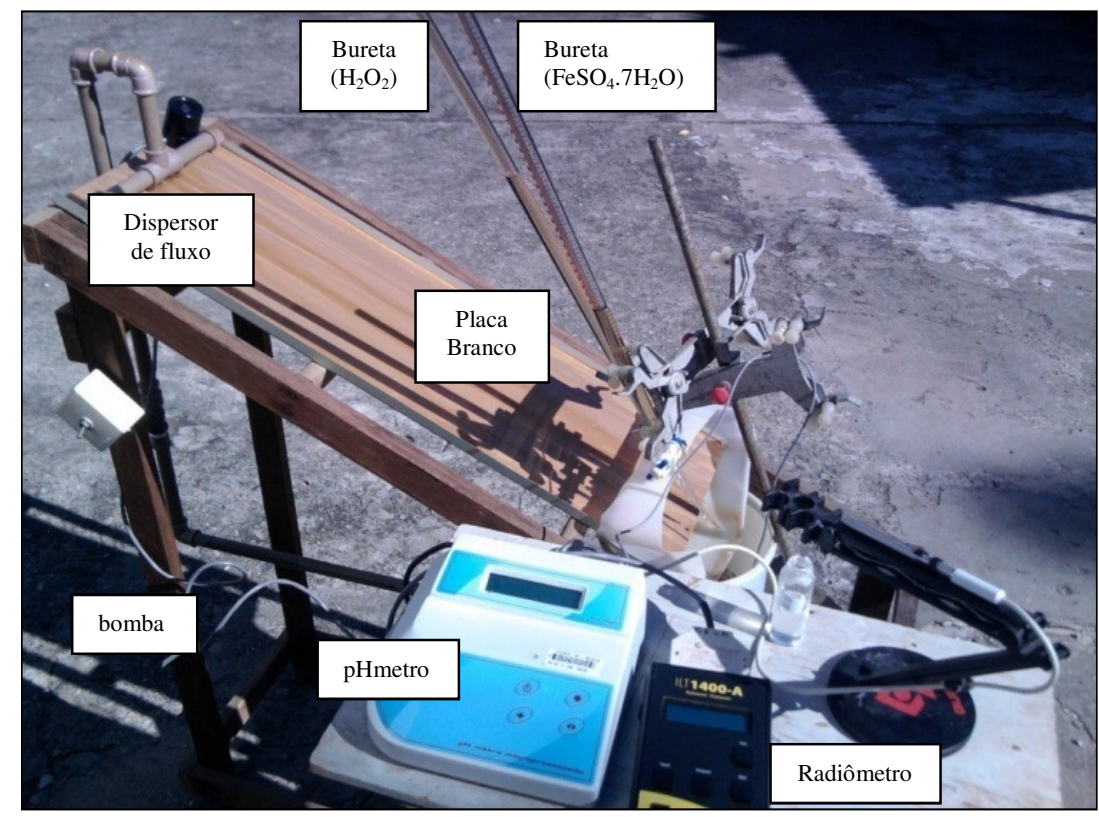

Figura 1. Layout do Reator Solar.

O processo fotocatalítico foi otimizado por um planejamento fatorial fracionado $\left(2^{4-1}\right)$, com duplicata e triplicata no ponto central (19 experimentos), sendo as variáveis de entrada: $\mathrm{pH}$, intensidade média de radiação solar em três períodos do dia (manhã das 8:00 às 10:00 h; almoço das 12:00 às 14:00; tarde das 15:00 às 17:00 h), quantidades de $\mathrm{H}_{2} \mathrm{O}_{2}$ e Fe ${ }^{2+}$, como mostrado na Tabela 1. Para a variável resposta foi utilizada a redução percentual da carga orgânica em função de DQO. O modelo neural foi implementado utilizando o software MatLab R2010 e a análise estatística o Minitab.

Tabela 1. Fatores e níveis para o planejamento de experimento foto-Fenton de $3 \mathrm{~L}$ do chorume.

\begin{tabular}{lcccc}
\hline Variáveis de Entrada & Notação & Nível 1 & Nível 2 & Nível 3 \\
\hline $\mathbf{p H}$ & $\mathrm{A}$ & 2 & 3 & 4 \\
{$\left[\mathbf{H}_{\mathbf{2}} \mathbf{O}_{2}\right](\mathbf{g})$} & $\mathrm{B}$ & 48,5 & 60,6 & 72,8 \\
${\mathbf{R a d i a c ̧ a ̃ o ~ S o l a r ~}(\mathbf{U V})\left(\boldsymbol{\mu W} \mathbf{~ c m}^{-2}\right)}_{\left[\mathbf{F e}^{\mathbf{2}}\right](\mathbf{g})}^{\mathrm{C}}$ & $\mathrm{C}$ & 719 & 1012 & 860 \\
\hline
\end{tabular}

Por ser um sistema semi-batelada aberto, a taxa de evaporação de 216,2 $\mathrm{mL} \mathrm{h}^{-1}$ (média) foi minimizada com adição de água (COT $<1 \mathrm{mg} \mathrm{L}^{-1}$ ), evitando-se uma pré-concentração do 
chorume durante o tratamento oxidativo. Para a medição e maximização da radiação solar, o radiômetro era posicionado na mesma inclinação do reator, onde o suporte de madeira era rotacionado constantemente para a incidência da máxima radiação do sol.

\subsection{Procedimento relacionado ao modelo neural}

A rede feedforward com algoritmo de aprendizagem backpropagation mapeou um espaço multi-dimensional da forma representada pela (Equação 6).

$$
\triangle D Q O=f\left(t, p H,\left[\mathrm{H}_{2} \mathrm{O}_{2}\right], P_{U V},\left[\mathrm{Fe}^{2+}\right]\right)
$$

A variável de saída $\triangle_{D_{\ell}}$ representa o decréscimo da DQO calculada pela (Equação 7), em que $\mathrm{DQO}_{\mathrm{o}}$ representa Demanda Química de Oxigênio do chorume in natura, e $\mathrm{DQO}_{\mathrm{t}}$ o teor da DQO após t minutos de tratamento. No modelo neural proposto, os neurônios da camada de entrada representaram as variáveis independentes ou variáveis de entrada e o neurônio da camada de saída representou a variável dependente $\Delta_{\mathrm{D} Q \mathrm{O}}$.

$$
\Delta D Q O=\frac{D Q O_{o}-D Q O_{t}}{D Q O_{o}}
$$

Durante o processo de treinamento da rede foram efetuadas várias configurações quanto ao número de neurônios existentes na camada oculta. Dentre os resultados foi escolhida a configuração que atuou com nove (9) neurônios na camada oculta, pois foi a que apresentou o melhor coeficiente de correlação para os conjuntos de treinamento, validação e teste. $\mathrm{O}$ ambiente computacional utilizado foi a toolbox NNtool do software MatLab.

\section{RESULTADOS E DISCUSSÃO}

\subsection{Caracterização do chorume in natura e tratado}

A caracterização do chorume foi realizada segundo aos parâmetros físico-químicos mais relevantes, como pH, DQO, $\mathrm{DBO}_{5}$, Nitrogênio amoniacal e orgânico, Carbono Orgânico Total (COT), Sólidos Totais, fixos e dissolvidos, óleos e graxas, razão de biodegradabilidade $\left(\mathrm{DBO}_{5} / \mathrm{DQO}\right)$, alguns íons específicos e metais sendo mostrados na Tabela 2. Ressalta-se que para a caracterização do chorume tratado foi utilizado o que apresentou o maior percentual de redução de DQO na reação foto-Fenton solar, após o ajuste do $\mathrm{pH}(9,0)$ para a floculação e precipitação.

As concentrações dos parâmetros encontrados no chorume quando comparados àquelas permitidas pela legislação, indicou que há a necessidade de um tratamento antes do descarte deste lixiviado ao rio, destacando os seguintes parâmetros: concentrações de $\mathrm{DQO}, \mathrm{DBO}_{5}$, biodegradabilidade, óleos e graxas, nitrogênio amoniacal e do metal Prata (Ag).

A alta concentração de Prata (Ag) apresentada na caracterização do chorume, ocorreu possivelmente devido ao descarte das chapas de raio-x no lixo urbano, que contém esse metal em sua composição, e que não foram reciclados em consultórios médicos e hospitais, apenas separados dos lixos hospitalares classificados como perigosos (classe 1).

Em relação aos parâmetros sem limitação de concentração máxima, destaca-se a diminuição significativa dos sólidos (fixos e voláteis) e a alteração acentuada nas características visuais (cor e turbidez).

O resíduo gerado após a precipitação do íon ferroso/férrico em meio alcalino, após o processo de oxidação, pode ser reaproveitado como reagente no processo novamente. Logo, otimizar o custo do processo. A segunda alternativa é reutilizar esse lodo formado para indústria de materiais cerâmicos, como: telhas e tijolos, para suprir a demanda da indústria 
civil. Sabendo que um resíduo formado deixa de ser um passivo ambiental quando transformado em subproduto no processo (CETESB, 1993).

De acordo com a lei Federal e Estadual (governo de São Paulo) é recomendado o mínimo na redução dos valores de $\mathrm{DBO}_{5}\left(<60 \mathrm{mg} \mathrm{O}_{2} \mathrm{~L}^{-1}\right)$ ou $80 \%$ na sua remoção.

Tabela 2. Caracterização Química do Chorume in natura e pré-tratado do aterro sanitário.

\begin{tabular}{|c|c|c|c|}
\hline Parâmetros & in natura & Pré-tratado & Legislação $^{(*)}$ \\
\hline $\mathrm{COT}\left(\mathrm{mg} \mathrm{C} \mathrm{L} \mathrm{L}^{-1}\right)$ & 368,6 & 65,9 & - \\
\hline $\mathrm{DQO}\left(\mathrm{mg} \mathrm{O}_{2} \mathrm{~L}^{-1}\right)$ & 3552,2 & 402,8 & - \\
\hline $\mathrm{DBO}\left(\mathrm{mg} \mathrm{O}_{2} \mathrm{~L}^{-1}\right)$ & 397,4 & 166,4 & 60 \\
\hline DBO/DQO & 0,11 & 0,41 & - \\
\hline $\mathrm{pH}$ & 8,23 & 9,34 & 5,0 a 9,0 \\
\hline Óleos e Graxas (mg L $\left.{ }^{-1}\right)$ & 165,1 & 12,0 & 100 \\
\hline Sólidos Totais ( $\mathrm{mg} \mathrm{L}^{-1)}$ & 6035 & 1134 & - \\
\hline Sólidos Fixos $\left(\mathrm{mg} \mathrm{L}^{-1}\right)$ & 1032 & 139 & - \\
\hline Sólidos Voláteis $\left(\mathrm{mg} \mathrm{L}^{-1}\right)$ & 5003 & 995 & - \\
\hline Turbidez (NTU) & 630,0 & 3,95 & 40 \\
\hline Cor (mg Pt-Co L $\left.{ }^{-1}\right)$ & 1763,2 & 13,7 & 100 \\
\hline Cloreto $\left(\mathrm{mg} \mathrm{Cl}^{-} \mathrm{L}^{-1}\right)$ & 246,1 & 114,2 & - \\
\hline 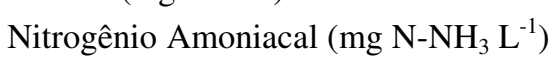 & 1582,3 & 425,3 & 20 \\
\hline Nitrogênio Orgânico $\left(\mathrm{mg} \mathrm{N}_{\mathrm{org}} \mathrm{L}^{-1}\right)$ & 860,0 & 652,1 & - \\
\hline Nitrito $\left(\mathrm{mg} \mathrm{NO}_{2}^{-} \mathrm{L}^{-1}\right)$ & 0,30 & 0,22 & - \\
\hline Nitrato $\left(\mathrm{mg} \mathrm{NO}_{3}^{-} \mathrm{L}^{-1}\right)$ & 2,10 & 1,45 & - \\
\hline Nitrogênio Total $\left(\mathrm{mg} \mathrm{N}_{\mathrm{T}} \mathrm{L}^{-1}\right)$ & 2444,7 & 1079,1 & - \\
\hline Fósforo Total $\left(\mathrm{mg} \mathrm{P} \mathrm{L}^{-1}\right)$ & 2,10 & 0,90 & - \\
\hline Arsênio (mg As L $\left.{ }^{-1}\right)$ & 0,016 & 0,009 & 0,2 \\
\hline Cádmio (mg Cd L $\left.{ }^{-1}\right)$ & 0,091 & 0,083 & 0,2 \\
\hline Cromo Total ( $\left.\mathrm{mg} \mathrm{Cr} \mathrm{L}^{-1}\right)$ & 0,256 & 0,016 & 5,0 \\
\hline Chumbo (mg Pb L $\left.{ }^{-1}\right)$ & 0,209 & 0,062 & 0,5 \\
\hline Ferro total $\left(\mathrm{mg} \mathrm{Fe} \mathrm{L}^{-1}\right)$ & 4,300 & 0,391 & 15,0 \\
\hline Manganês (mg Mn L ${ }^{-1}$ ) & 0,037 & 0,022 & 1,0 \\
\hline Níquel $\left(\mathrm{mg} \mathrm{Ni} \mathrm{L}^{-1}\right)$ & 0,073 & 0,042 & 2,0 \\
\hline Prata $\left(\mathrm{mg} \mathrm{Ag} \mathrm{L}^{-1}\right)$ & 0,72 & 0,63 & 0,02 \\
\hline Zinco (mg Zn L ${ }^{-1}$ ) & 0,089 & 0,049 & 5,0 \\
\hline
\end{tabular}

*Valores permitidos, quando apresentados, referem-se aos limites permitidos pela resolução do CONAMA 430/2011 (Brasil, 2011).

Os resultados mostraram a eficiência de $58,2 \% \mathrm{DBO}_{5}$ e $88,7 \%$ DQO no processo foto-Fenton solar, onde ainda não atendem a legislação. No entanto, o processo mostrou viabilidade técnica, onde utilizando a luz solar concomitante ao reagente de Fenton, conseguiu obter um aumento na biodegradabilidade, elevando a razão $\mathrm{DBO}_{5} / \mathrm{DQO}$ de 0,11 a 0,41 (com um incremento de $273 \%$ ). Após o tratamento foto-oxidativo, este resultado indica que o chorume aumentou significativamente a sua biodegradabilidade (Malato et al., 2002), mostrando, assim, condições físico-químicas favoráveis para ser tratado biologicamente, com melhoras nas etapas operacionais como a diminuição do tempo de retenção hidráulico e da formação de lodo no tratamento por lodo ativado. 


\subsection{Custo do processo}

A avaliação econômica (consumo energético e reagentes) no tratamento do chorume, de acordo com o planejamento fracionado $\left(2^{4-1}\right)$, considerou apenas o processo foto-Fenton Solar. A energia consumida pelos equipamentos no processo foto-Fenton com duração de 2 horas foram: pHmetro (PH21 pH/mV HANNA) e a bomba centrífuga (BOMAX, Modelo NH-30PX-T).

Essa estimativa do consumo energético dos equipamentos do processo foto-Fenton solar foi realizada através da medida direta da respectiva energia consumida, pelo equipamento ICEL ME-2500 (220V e $60 \mathrm{~Hz})$, certificado de conformidade com a numeração (201111011512) e seu custo calculado através da cotação da potência nacional (KWh) (Portal Business Brasil, 2012). E a estimativa de consumo de reagentes, de acordo com os níveis da planilha (Tabela 1), foi calculado considerando-se os seguintes reagentes e concentrações: $\mathrm{H}_{2} \mathrm{SO}_{4}\left(98 \% \mathrm{~m} \mathrm{~m}^{-1}\right), \mathrm{NaOH}\left(98 \% \mathrm{~m} \mathrm{~m}^{-1}\right), \mathrm{H}_{2} \mathrm{O}_{2}\left(30 \% \mathrm{~m} \mathrm{~m}^{-1}\right)$ e $\mathrm{FeSO}_{4} \cdot 7 \mathrm{H}_{2} \mathrm{O}\left(98 \% \mathrm{~m} \mathrm{~m}^{-1}\right)$, com base de cotação no Guia do Químico (2012).

O pHmetro consumiu $0,00166 \mathrm{KWh}$ para o controle operacional e a bomba centrífuga 0,0276 KWh para o fluxo do efluente sobre o reator, totalizando $0,02926 \mathrm{KWh}$, considerandose o tempo total de reação para todos os experimentos realizados.

A otimização do processo foto-Fenton, em função da redução de DQO, foi avaliada através do cálculo final do consumo total (energia + reagente) à relação custo/benefício (menor é melhor), realizado em cada experimento, conforme mostrado na Tabela 3.

Os resultados obtidos da Tabela 3 foram realizados em duplicatas e apresentaram valores de redução de DQO com baixo desvio padrão $(\mathrm{d}<0,05)$, obtendo, assim, uma maior confiabilidade nos resultados. A redução percentual de DQO do experimento 13 (o melhor com redução da concentração de DQO de 88,7 \%) foi avaliada através do cálculo final do consumo total (energia + reagente), onde o custo de energia ( $\mathrm{R} \$ 0,0095)$ e o consumo de reagente $(\mathrm{R} \$ 0,3705)$ totalizaram $\mathrm{R} \$ 0,38$ para os $3 \mathrm{~L}$ do reator, durante as 2 horas de reação fotocatalítica. Também, os resultados da Tabela 3 mostram que o melhor resultado custo/benefício da planilha não está relacionado com o melhor rendimento de degradação (redução da DQO). O melhor desempenho na degradação fotocatalítica e o seu respectivo resultado do custo/benefício não é o melhor da planilha, devido ao seu alto consumo de reagentes, principalmente $\mathrm{o}_{2} \mathrm{O}_{2}\left(30 \% \mathrm{~m} \mathrm{~m}^{-1}\right)$, obtendo a $4^{\mathrm{a}}$ menor relação custo/benefício $(4,28)$ entre todos os experimentos.

Em relação ao melhor custo/benefício, o melhor experimento foi o 1, cujo valor foi de 3,26 (sendo a sua duplicata com 3,34, experimento 11), com uma redução na DQO de 84,4 \%. $\mathrm{Na}$ avaliação geral, buscando-se uma viabilidade econômica no processo foto-Fenton, é melhor utilizar as variáveis utilizadas nos experimentos 1 e 11 , mesmo com uma menor redução da DQO (diferença de 4,3 \%), mas com uma economia de $\mathrm{R} \$ 35,67 \mathrm{~m}^{-3}$ de chorume tratado (cerca de $28,1 \%$ ). Os níveis das variáveis para esse experimento com melhor custo/benefício, considerando-se $3 \mathrm{~L}$ de chorume, são: $\mathrm{pH}$ em 4, quantidades dos reagentes $\mathrm{H}_{2} \mathrm{O}_{2}$ de 48,5 g e Fe ${ }^{2+}$ de $6,1 \mathrm{~g}$ e UV no período da tarde.

\subsection{Modelo neural proposto}

Numa fase anterior à implementação do modelo de redes neurais e sua otimização, os dados foram transformados de modo que as variáveis dependentes e independentes exibissem características de distribuições particulares (Olden e Jackson, 2002). No presente trabalho, os dados foram normalizados de forma a possuírem média zero e desvio padrão igual a 1.

Os resultados e os níveis dos fatores de entrada do planejamento fatorial fracionado $2^{4-1}$ são apresentados na Tabela 4. Realça-se que os 247 pontos experimentais componentes do modelo neural foram obtidos através da planilha experimental, com coleta de pontos em 
tempos de 10 minutos durante cada experimento, tendo como base a matriz experimental da Tabela 4.

Tabela 3. Custo ( $\mathrm{R} \$$ ) dos reagentes e energia do processo foto-Fenton solar para o tratamento de $3 \mathrm{~L}$ de chorume em 2-h de reação, segundo planejamento de experimentos.

\begin{tabular}{|c|c|c|c|c|c|c|c|c|}
\hline \multirow{3}{*}{ Exp. } & \multicolumn{4}{|c|}{ Reagentes } & \multirow{3}{*}{ Energia } & \multirow{3}{*}{$\begin{array}{c}\text { Custo } \\
\text { Total } \\
\text { (CT) } \mathbf{R} \$\end{array}$} & \multirow{3}{*}{$\begin{array}{c}\text { Redução } \\
\text { DQO } \\
(\% \text { red })\end{array}$} & \multirow{3}{*}{ 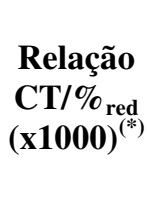 } \\
\hline & \multicolumn{2}{|c|}{ Ajuste de pH } & \multicolumn{2}{|c|}{ Reagente de Fenton } & & & & \\
\hline & $\mathrm{NaOH}$ & $\mathrm{H}_{2} \mathrm{SO}_{4}$ & $\mathrm{H}_{2} \mathrm{O}_{2}$ & $\mathrm{FeSO}_{4} \cdot 7 \mathrm{H}_{2} \mathrm{O}$ & & & & \\
\hline 1 & 0,0036 & 0,0649 & 0,147 & 0,050 & 0,0095 & 0,275 & 84,4 & 3,26 \\
\hline 2 & 0,0074 & 0,0629 & 0,147 & 0,050 & 0,0095 & 0,277 & 54,6 & 5,07 \\
\hline 3 & 0,0074 & 0,0629 & 0,147 & 0,079 & 0,0095 & 0,306 & 67,9 & 4,50 \\
\hline 4 & 0,0054 & 0,0619 & 0,185 & 0,065 & 0,0095 & 0,327 & 75,3 & 4,34 \\
\hline 5 & 0,0036 & 0,0649 & 0,147 & 0,079 & 0,0095 & 0,304 & 47,0 & 6,47 \\
\hline 6 & 0,0074 & 0,0629 & 0,147 & 0,050 & 0,0095 & 0,277 & 52,3 & 5,29 \\
\hline 7 & 0,0074 & 0,0629 & 0,223 & 0,079 & 0,0095 & 0,382 & 72,3 & 5,28 \\
\hline 8 & 0,0074 & 0,0629 & 0,223 & 0,050 & 0,0095 & 0,353 & 70,1 & 5,03 \\
\hline 9 & 0,0054 & 0,0619 & 0,185 & 0,065 & 0,0095 & 0,327 & 74,3 & 4,40 \\
\hline 10 & 0,0074 & 0,0629 & 0,223 & 0,079 & 0,0095 & 0,382 & 71,1 & 5,37 \\
\hline 11 & 0,0036 & 0,0649 & 0,147 & 0,050 & 0,0095 & 0,275 & 82,2 & 3,34 \\
\hline 12 & 0,0036 & 0,0649 & 0,223 & 0,079 & 0,0095 & 0,380 & 87,6 & 4,33 \\
\hline 13 & 0,0036 & 0,0649 & 0,223 & 0,079 & 0,0095 & 0,380 & 88,7 & 4,28 \\
\hline 14 & 0,0036 & 0,0649 & 0,223 & 0,050 & 0,0095 & 0,351 & 69,0 & 5,08 \\
\hline 15 & 0,0036 & 0,0649 & 0,147 & 0,079 & 0,0095 & 0,304 & 49,0 & 6,21 \\
\hline 16 & 0,0074 & 0,0629 & 0,223 & 0,050 & 0,0095 & 0,353 & 66,3 & 5,32 \\
\hline 17 & 0,0074 & 0,0629 & 0,147 & 0,079 & 0,0095 & 0,306 & 68,5 & 4,46 \\
\hline 18 & 0,0054 & 0,0619 & 0,185 & 0,065 & 0,0095 & 0,327 & 78,4 & 4,17 \\
\hline 19 & 0,0036 & 0,0649 & 0,223 & 0,050 & 0,0095 & 0,351 & 66,1 & 5,31 \\
\hline
\end{tabular}

(*) Fator para avaliar a relação custo-benefício.

O número ótimo de neurônios da camada oculta foi determinado baseado no valor mínimo do MSE (Mean Square Error) dos conjuntos de treinamento, validação e teste, variando-se o número de neurônios de 1 a 25 . A Figura 2 apresenta as relações entre MSE e o número de épocas necessários para se obter o valor mínimo de MSE.

As Figuras 3A, 3B, 3C e 3D apresentam os ajustes obtidos respectivamente para os conjuntos de treinamento, teste, validação e totalidade dos pontos experimentais.

A matriz de entrada foi composta por 247 amostras e este conjunto foi dividido em subconjuntos de treinamento $(50 \%)$, de validação $(25 \%)$ e de teste $(25 \%)$, com o objetivo de verificação do poder de generalização da rede neural obtida.

Observa-se resultados de coeficientes de correlação acima de 0,94 para os conjuntos de treinamento, validação e teste, confirmando o poder de generalização do modelo neural obtido. 
Tabela 4. Variação percentual de DQO para cada experimento foto-Fenton solar.

\begin{tabular}{|c|c|c|c|c|c|}
\hline \multicolumn{6}{|c|}{ Fatorial Fracionado $2^{4-1}$} \\
\hline \multirow{2}{*}{$\operatorname{Exp}$} & pH & $\mathbf{H}_{2} \mathbf{O}_{2}{ }^{(*)}$ & UV & $\mathrm{Fe}^{2+(*)}$ & DQO \\
\hline & (A) & (B) & (C) & (D) & $(\%)$ \\
\hline 1 & 4 & 48,5 & Tarde & 6,1 & 84,4 \\
\hline 2 & 2 & 48,5 & Manhã & 6,1 & 54,6 \\
\hline 3 & 2 & 48,5 & Tarde & 9,7 & 67,9 \\
\hline 4 & 3 & 60,6 & Almoço & 7,9 & 75,3 \\
\hline 5 & 4 & 48,5 & Manhã & 9,7 & 47,0 \\
\hline 6 & 2 & 48,5 & Manhã & 6,1 & 52,3 \\
\hline 7 & 2 & 72,8 & Manhã & 9,7 & 72,3 \\
\hline 8 & 2 & 72,8 & Tarde & 6,1 & 70,1 \\
\hline 9 & 3 & 60,6 & Almoço & 7,9 & 74,3 \\
\hline 10 & 2 & 72,8 & Manhã & 9,7 & 71,1 \\
\hline 11 & 4 & 48,5 & Tarde & 6,1 & 82,2 \\
\hline 12 & 4 & 72,8 & Tarde & 9,7 & 87,6 \\
\hline 13 & 4 & 72,8 & Tarde & 9,7 & 88,7 \\
\hline 14 & 4 & 72,8 & Manhã & 6,1 & 69,0 \\
\hline 15 & 4 & 48,5 & Manhã & 9,7 & 49,0 \\
\hline 16 & 2 & 72,8 & Tarde & 6,1 & 66,3 \\
\hline 17 & 2 & 48,5 & Tarde & 9,7 & 68,5 \\
\hline 18 & 3 & 60,6 & Almoço & 7,9 & 78,4 \\
\hline 19 & 4 & 72,8 & Manhã & 6,1 & 66,1 \\
\hline
\end{tabular}

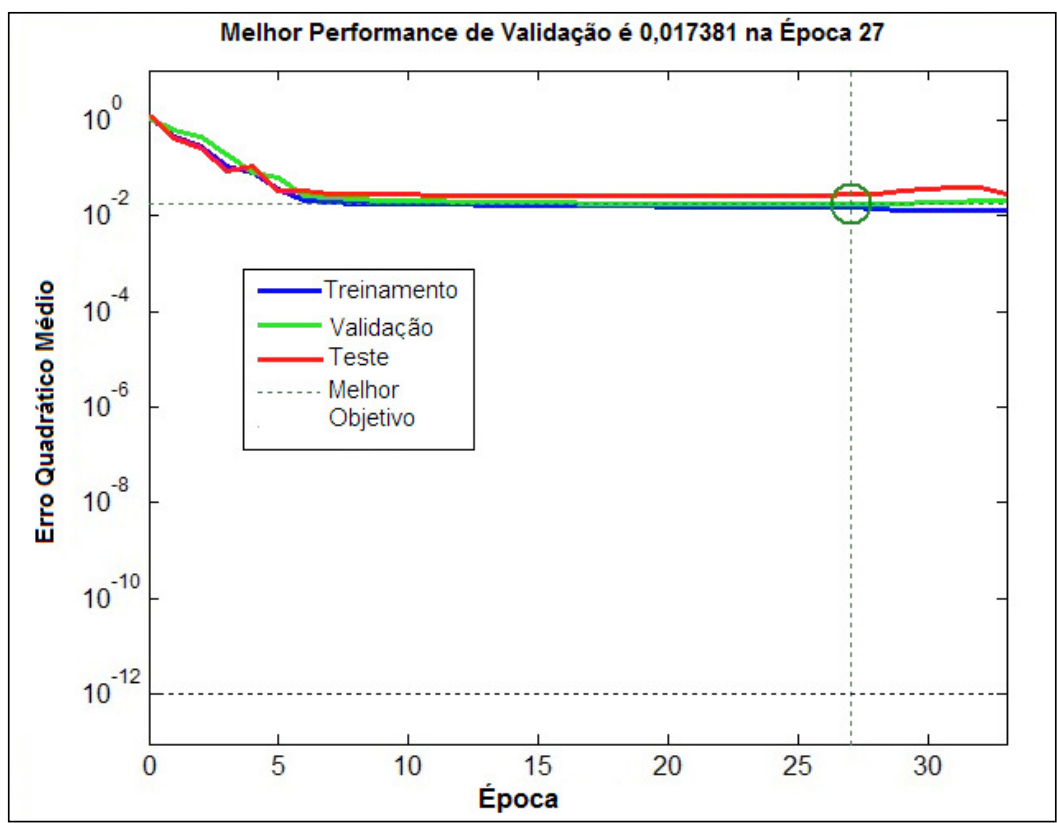

Figura 2. Erro Quadrático Médio. 

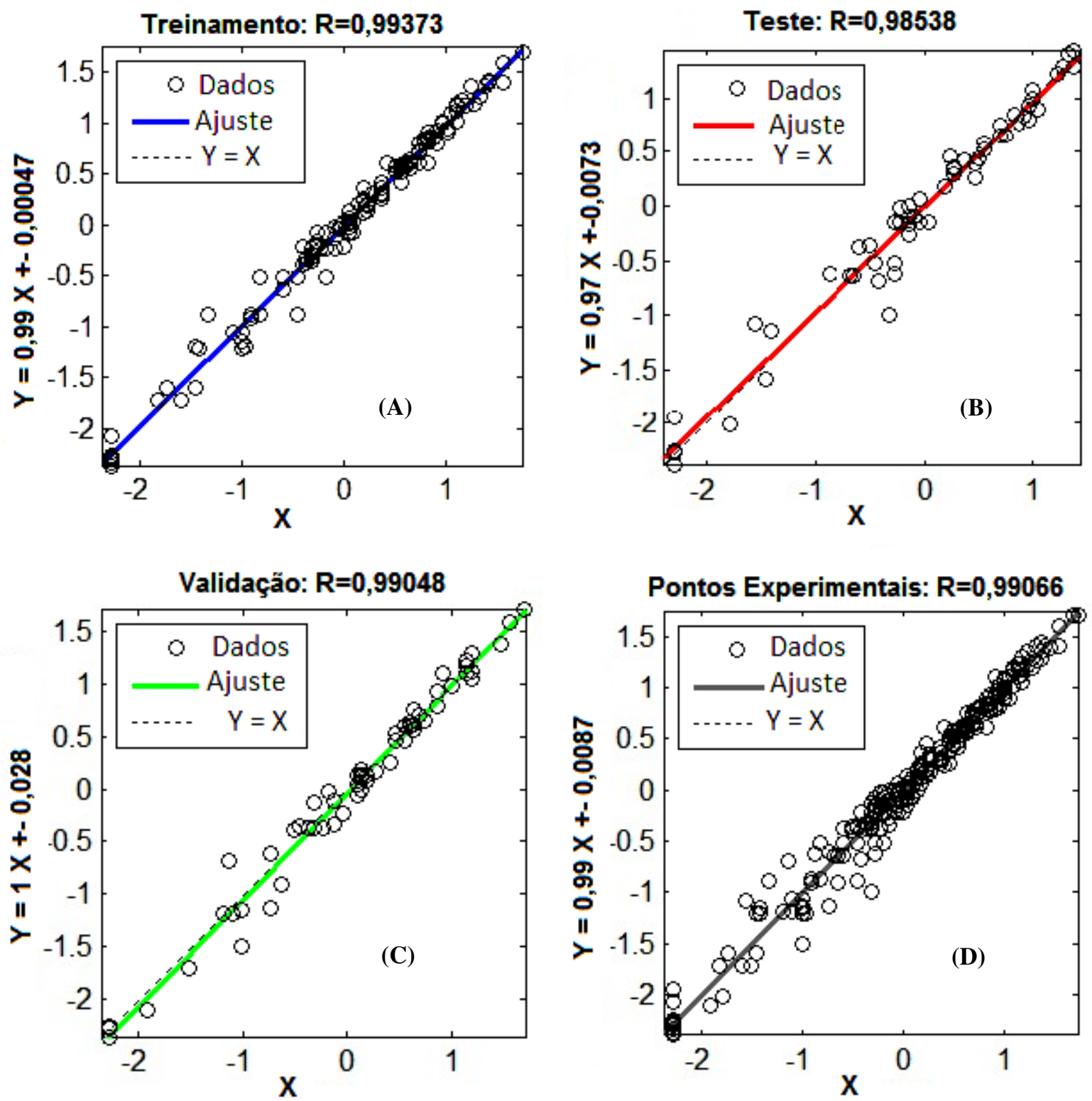

Figura 3. Ajuste dos conjuntos em função de: (A) Treinamento; (B) Teste; (C) Validação; (D) Pontos Experimentais, onde Y são os valores preditos pelo modelo neural e $\mathrm{X}$ os valores reais dos experimentos.

\subsection{Análise dos efeitos}

A Tabela 5 apresenta a análise de variância dos fatores envolvidos no tratamento do chorume com o processo foto-Fenton solar em função da \% redução de DQO.

Pela análise de variância, verificou-se que os fatores 1, 2 e 3 apresentaram efeito significativo $(\mathrm{P}<0,05)$ na redução percentual DQO. $\mathrm{O}$ fator 4 não apresentou significância no processo, dentro do intervalo de confiança de $95 \%$.

A Figura 4 proporciona uma noção qualitativa da importância dos efeitos dos fatores principais. $\mathrm{O}$ gráfico dos efeitos principais mostra que deve existir curvatura para a variação de DQO, visto que a média dos pontos centrais não está posicionada próxima da reta dos valores médios de variação da DQO. 
Tabela 5. Análise de variância (ANOVA) obtida a partir dos valores médios de redução percentual de DQO.

\begin{tabular}{lccccc}
\hline \multicolumn{1}{c}{ Termo } & Efeito & Coeficiente & $\begin{array}{c}\text { Erro } \\
\text { Quadrático }\end{array}$ & $\mathbf{T}$ & $\mathbf{P}$ \\
\hline Constante & 68,601 & 0,4312 & 159,09 & 0,000 & \\
$\mathbf{p H}$ & 6,416 & 3,208 & 0,4312 & 7,44 & 0,000 \\
$\mathbf{H}_{\mathbf{2}} \mathbf{O}_{2}$ & 10,719 & 5,359 & 0,4312 & 12,43 & 0,000 \\
$\mathbf{U V}$ & 16,844 & 8,422 & 0,4312 & 19,53 & 0,000 \\
$\mathbf{F e}^{2+}$ & 0,926 & 0,463 & 0,4312 & 1,07 & 0,308 \\
$\mathbf{p H} \mathbf{H}_{2} \mathbf{O}_{2}$ & 1,564 & 0,782 & 0,4312 & 1,81 & 0,100 \\
$\mathbf{p H} \mathbf{U V}^{2}$ & 11,214 & 5,607 & 0,4312 & 13,00 & 0,000 \\
$\mathbf{p H} \mathbf{F e}^{2+}$ & $-8,204$ & $-4,102$ & 0,4312 & $-9,51$ & 0,000 \\
$\mathbf{P o n t o}$ Central & & 7,393 & 1,0852 & 6,81 & 0,000 \\
\hline
\end{tabular}

Nota: Coeficiente de Determinação = 98,90\%; Coeficiente de Determinação Ajustado = 98,03\%.

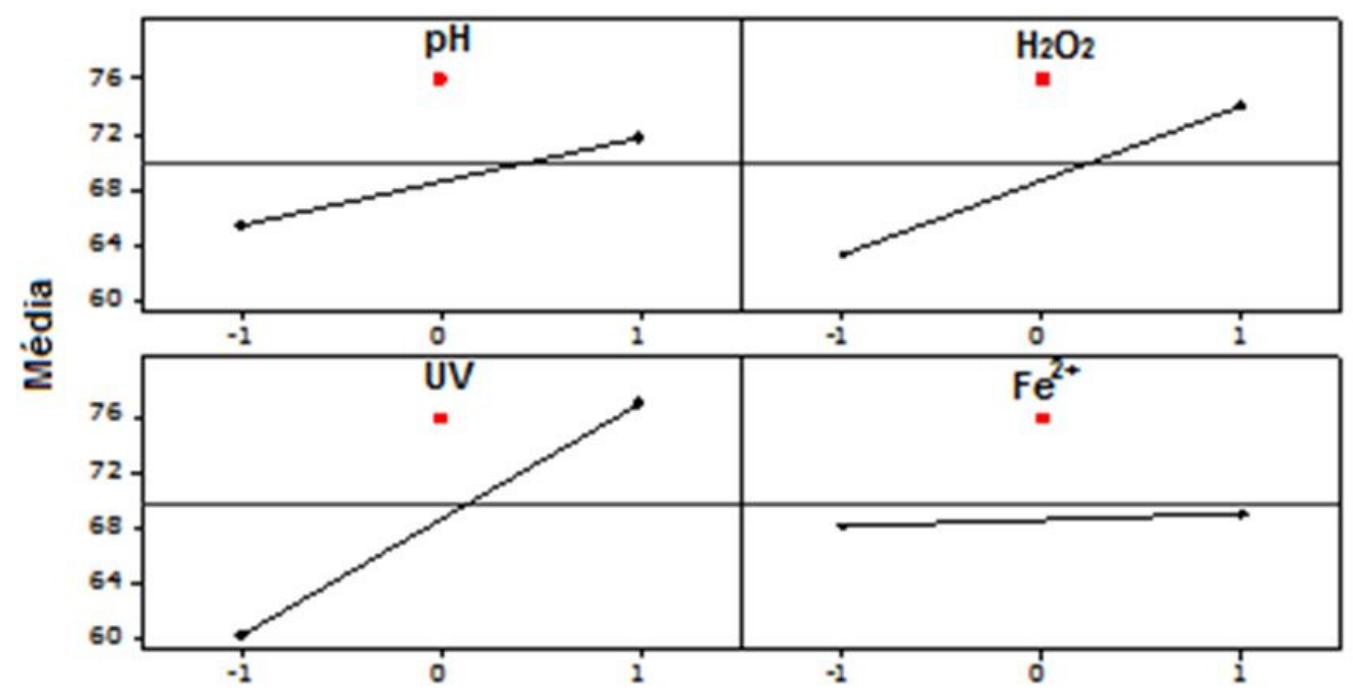

Figura 4. Gráfico dos efeitos em relação a \% redução de DQO.

$\mathrm{O}$ fator "D" referente à quantidade $\mathrm{Fe}^{2+}$ obteve uma baixa significância, possivelmente devido à inerente turvação verificada após a sua adição durante o processo de oxidação, em todos os níveis, dificultando a ação da incidência da luz solar. Mesmo assim, este termo não deve ser retirado do modelo, visto que existe uma significância deste fator interagindo com o fator $\mathrm{pH}$.

No rendimento do processo foto-Fenton solar foi relacionado com a quantidade ótima de oxidante $\left(\mathrm{H}_{2} \mathrm{O}_{2}\right)$, utilizado no processo oxidativo, bem como o período de reação. Por esse foco podemos notar que os experimentos realizados nos período da tarde e almoço, apresentaram valores de porcentagem de redução de DQO na faixa de $80 \%$, mostrando que a presença do UV potencializa a reação de formação do radical hidroxila (Loures, 2011).

A Figura 5 mostra o gráfico de contorno da variável resposta DQO em função das concentrações de $\mathrm{Fe}^{2+}$ e do $\mathrm{H}_{2} \mathrm{O}_{2}$ no tratamento foto-Fenton solar, onde pode ser observado que no nível mais alto de suas quantidades obtêm-se reduções acima de $80 \%$. 


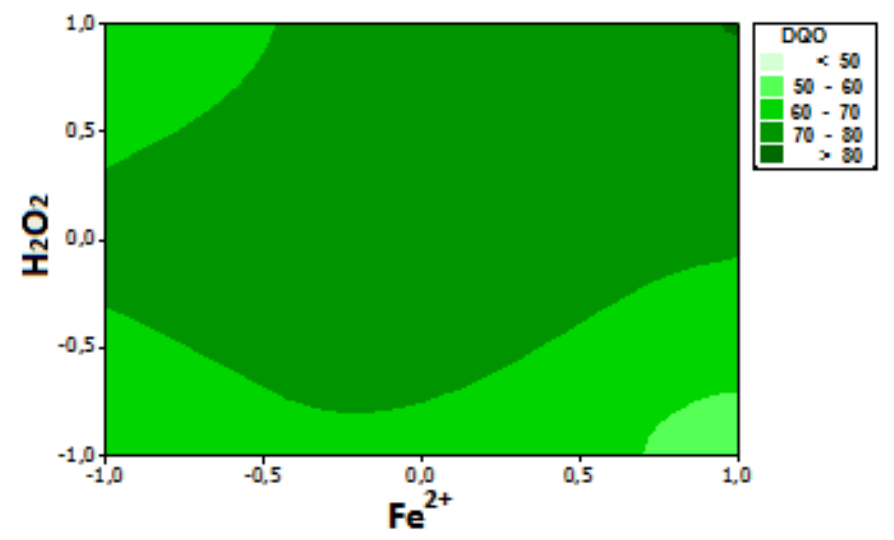

Figura 5. Variação da DQO em função do $\mathrm{Fe}^{2+} \mathrm{e}$ $\mathrm{H}_{2} \mathrm{O}_{2}$ do processo foto-Fenton solar no tratamento de chorume.

\section{CONCLUSÃO}

Uma rede neural feedforward backpropagation com 3 camadas foi otimizada para predizer o grau de degradação de chorume in natura utilizando processo foto-fenton solar. A configuração do modelo neural que proporcionou o menor valor de MSE utilizou uma função de transferência logaritmo sigmoidal (logsig) na camada oculta com 9 neurônios e função de transferência linear (purelin) na camada de saída. O algoritmo de treinamento utilizado foi Levenberg-Marquardt backpropagation.

Além disso, a proposta de um tratamento ou pré-tratamento de chorume pelo processo foto-Fenton Solar teve como sua maior eficiência em $88 \%$ na redução de DQO. Segundo legislação ambiental, o parâmetro de controle para descarte em água superficial (DBO) não apresentou a concentração estabelecida após a oxidação do chorume, o que mostra que o chorume deve passar por um outro tipo de tratamento. Como a relação DBO/DQO teve um incremento de 0,3 unidades, mostra uma viabilidade para o tratamento biológico por lodo ativado.

Dentro do delineamento do planejamento de experimentos avaliado para a degradação de chorume in natura pelo processo foto-Fenton, o melhor resultado em função da redução de DQO obtido foi de 88,7 \% . Mas, a viabilidade econômica e operacional do processo fotooxidativo tendeu a uma eficiência de $84,4 \%$ na redução de DQO, chegando-se num valor de $\mathrm{R} \$ 91,67 \mathrm{~m}^{-3}$, com uma economia de $\mathrm{R} \$ 35,67$ para cada $\mathrm{m}^{3}$ de chorume tratado. Em relação ao custo de cada parâmetro avaliado, como em todo o processo Fenton, a variável peróxido de hidrogênio foi a mandatória. Com esse tipo de tratamento realizado, segundo os dados do planejamento de experimentos propostos, não foi possível otimizar a relação entre $\mathrm{H}_{2} \mathrm{O}_{2} \mathrm{e}$ $\mathrm{Fe}^{2+}$, que deve ser criteriosamente avaliado em função dos seus elevados valores comerciais.

Os resultados preditos pela rede neural aproximaram-se dos resultados experimentais com coeficientes de correlação acima de 0,94 para os conjuntos de treinamento, validação e teste, evidenciando o poder de generalização do modelo proposto.

A utilização de redes neurais no processo de degradação de efluentes por processos foto oxidativos pode ser acoplada à análise estatística, fornecendo uma forma de modelagem matemática entre representatividade do modelo e tempo computacional. Realça-se, desta forma, a aplicabilidade de técnicas de redes neurais e análises estatísticas no equacionamento dos problemas da área ambiental, em particular na predição e análises de processos de tratamento de efluentes.

Algumas características dos modelos neurais apresentam-se como vantagens na análise de processos de degradação de efluentes, sendo destacadas a capacidade de modelar processos 
não-lineares e complexos, como o processos foto-Fenton, revestidos de não-linearidades com a ação de interferentes na análise de parâmetros ambientais como a DQO. A influência aleatória da radiação ultravioleta em função de condições ambientais apresenta-se como forte fator não linear em dados empíricos, sendo parâmetros incertos que variam com o tempo. A utilização de modelos que envolvem processos de radiação de caráter determinístico reveste de complexidade matemática a modelagem de processos foto-fenton, pois envolvem a solução de equações de energia, balanços de massa e de energia térmica. Neste sentido, a modelagem neural pode ser aplicada facilmente em ambientes computacionais como o software Matlab. A rede neural proposta mapeou um espaço multidimensional da forma $\triangle D Q O=f\left(t, p H,\left[\mathrm{H}_{2} \mathrm{O}_{2}\right], P_{U V},\left[\mathrm{Fe}^{2+}\right]\right)$. Entretanto, realça-se que modelos neurais são baseados em dados históricos do processo em estudo e que esta base de conhecimento não é desperdiçada podendo ser inserida em novos processos de modelagem do efluente objeto de estudo deste trabalho. Em particular, poderíamos inserir no modelo proposto dados de um processo de degradação que envolvesse uma nova variável de entrada, ou seja, uma camada de entrada com um número de neurônios diferentes da base de dados inicial.

\section{AGRADECIMENTOS}

Agradecimentos a CAPES (Coordenação de Aperfeiçoamento de Pessoal de Nível Superior) pelo apoio financeiro. E aos autores do projeto de pesquisa de tratamento de chorume financiado pela FAPESP (Fundação de Amparo à Pesquisa do Estado de São Paulo) 2009/17650-2 que forneceram o apoio técnico ao trabalho.

\section{REFERÊNCIAS}

AMERICAN PUBLIC HEALTH ASSOCIATION - APHA; AMERICAN WATER WORKS ASSOCIATION - AWWA; WATER ENVIRONMENTAL FEDERATION - WEF. Standard methods for the examination of water and wastewater. 22. ed. Washington, DC., 2009.

BRASIL. Conselho Nacional do Meio Ambiente. Resolução no 430 de 13 de maio de 2011. Dispõe sobre as condições e padrão de lançamento de efluentes complementa e altera a Resolução no 357, de 17 de março de 2005. Brasília: MMA, 2011. 9p.

CERQUEIRA, E. O.; ANDRADE, J. C.; POPPI, R. J. Redes neurais e suas aplicações em calibração multivariada. Química Nova, v. 24, n. 6, 864-873, 2001. http://dx.doi.org/10.1590/S0100-40422001000600025

ÇINAR, O. New tool for evaluation of performance of wastewater treatment plant: artificial neural network. Process Biochemistry, v. 40, n. 3, p 2980-2984, 2005. http://dx.doi.org/10.1016/j.procbio.2005.01.012

COMPANHIA DE TECNOLOGIA DE SANEAMENTO AMBIENTAL - CETESB. Resíduos sólidos industriais. 1993. Disponível em: <http://www.cetesb.sp.gov.br>. Acesso em: 12 dez. 2011.

ELMOLLA, E. S.; CHAUDHURI, M.; ELTOUKHY, M. M. The use of artificial neural network (ANN) for modeling of COD renoval from antibiotic aqueous solution by the Fenton process. Journal of Hazardous Material, v. 179, n.1, p 127-134, 2010. http://dx.doi.org/10.1016/j.jhazmat.2010.02.068 
GIORDANI, D. S Estudo comparativo entre observador de estado não-linear de alto ganho e calorimetria associada a redes neurais artificiais para previsão de composição de copolímeros produzidos em emulsão com altos teores sólido. 2003. 90f. Tese (Doutorado) - Faculdade de Engenharia Química, Universidade Estadual de Campinas, Campinas, 2003.

GIROTO, J. A. Estudo do processo de degradação fotoquímica de soluções aquosas de álcool polivinílico. 2002. 93f. Dissertação (Mestrado) - Escola Politécnica de São Paulo, Universidade de São Paulo, São Paulo, 2002.

GUIA DO QUÍMICO. Cotação de reagentes Químicos. 2012. Disponível em: <http://www.guiaquimico.com.br>. Acesso em: 29 fev. 2012.

GUIMARÃES, O. L. C.; AQUINO, H. O. Q; OLIVEIRA, I. S.; SILVA, M. B.; IZÁRIO FILHO, H. J. et al. Prediction via Neural Networks of the Residual Hydrogen Peroxide used in Photo-Fenton Processes for Effluent Treatment. Chemical Engineering Technology, v. 30, n. 8, p. 1134-1139, 2007. http://dx.doi.org/10.1002/ceat.200700113

GUIMARÃES, O. L. C.; VILLELA FILHO, D. N.; SIQUEIRA, A. F.; IZÁRIO FILHO, H. J.; SILVA, M. B. Optimization of the AZO dyes decoloration process through neural networks: determination of the $\mathrm{H}_{2} \mathrm{O}_{2}$ addition critical point. Chemistry Engineering Journal, v. 141, n. 1/3, p. 35-41, 2008. http://dx.doi.org/10.1016/j.cej.2007.10.017

HAMED, M. M.; KHALAFALLAH, M. G.; HASSANIEN, E. A. Prediction of wastewater treatment plant performance using artificial neural networks. Environmental Modelling \& Software, v. 19, n. 4, p. 919-928, 2004. http://dx.doi.org/10.1016/j.envsoft.2003.10.005

HAYKIN, S. S. Redes neurais: princípios e prática. 2. ed. São Paulo: Artmed, 1999.

KATO, Y.; KUMAGAI, T.; NISHIOKA, H.; SUGIE, Y. The prediction of Chemical Oxygen Demand (COD) in waste water by UV-visible absorption spectrum - neural network. Oriental Journal of Chemistry, v. 17, n. 1, p. 1-8, 2001.

KJELDSEN P. I.; BARLAZ, M. A.; ROOKER, A. P.; BAUN, A.; LEDIN, A.; CHRISTENSEN, T. H. Present and long-term composition of MSW landfill leachate: a review. Critical Reviews in Environmental Science and Technology, v. 32, n. 5, p. 297-336, 2002. http://dx.doi.org/10.1080/10643380290813462

LIMA, L. S.; IZÁRIO FILHO, H. J.; CHAVES, F. J. M. Determinação da demanda bioquímica de oxigênio para teores $\leq 5 \mathrm{mg} \mathrm{L}^{-1} \mathrm{O}_{2}$. Revista Analítica, v. 25, n. 2, p. 52 57, 2006.

LOURES, C. C. A. Estudo da Aplicação de UV/FENTON $\left(\mathrm{Fe}^{2+}+\mathrm{H}_{2} \mathrm{O}_{2}\right)$ no Tratamento de Efluentes de Laticínio. 2011. 209 f. Dissertação (Mestrado em ciências) - Escola de Engenharia de Lorena, Universidade de São Paulo, Lorena, 2011.

MALATO, S.; BLANCO, J.; FERNANDEZ-ALBA, A. R.; AGUERA, A. Solar photocatalytic mineralization of commercial pesticides: acrinathrin. Chemosphere, v. 40, n. 8, p. 403-409, 2002. http://dx.doi.org/10.1016/S0045-6535(99)00267-2

NADTOCHENCO, V.; KIWI, J. Photoinduced Mineralization of Xylidine by the Fenton Reagent 2. Implications of precursors formed in the dark. Environmental Science \& Technology, v. 32, n. 21, p. 3282-3285, 1998. http://dx.doi.org/10.1021/es9709637 
NOGUEIRA, R. F. P.; TROVÓ, A. G.; SILVA, M. R. A.; VILLA, R. D. Fundamentos e Aplicações dos Processos Fenton e Foto-Fenton. Química Nova, v. 30, n. 2, p. 400-408, 2007. http://dx.doi.org/10.1590/S0100-40422007000200030

OLDEN, J. D.; JACKSON, D. A. Illuminating the "black box": a randomization approach for understanding variable contributions in artificial neural networks. Ecological Modelling, v. 154, n. 1, p. 135-150, 2002. http://dx.doi.org/10.1016/S03043800(02)00064-9

PAREEK, V. K.; BRUNGS, M. P.; ADESINA, A. A.; SHARAMA, R. Artificial neural network modeling of a multiphase photodegradation system. Journal of Photochemistry and Photobiology A: Chemistry, v. 149, n. 3, p. 139-146, 2002. http://dx.doi.org/10.1016/S1010-6030(01)00640-2

PORTAL BUSINESS BRASIL. Energia elétrica a terceira mais cara do país. 2012. Disponível em: http://sites.google.com/site/portalbusinessbrasil/home/energiabrasileira . Acesso em: 29/07/2012.

SVOZIL, D.; KVASNICKA. A; POSPÍCHAl, J. Introduction to multi-layer feed-forward neural networks. Chemometrics and Intelligent Systems, v. 39, n. 1, p. 43-62, 1997. http://dx.doi.org/10.1016/S0169-7439(97)00061-0

TELLES, C. A. S. Processos combinados para o tratamento de lixiviado de aterro sanitário. 2010. Dissertação (Mestrado em Engenharia Química) - Universidade do Rio de Janeiro, Universidade Federal do Rio de Janeiro, Rio de Janeiro, 2010.

VILAR, J. P. V; MOREIRA, J. M. S; BOAVENTURA, R. A. R. Solar photo-Fenton as a preoxidation step for biological treatment of landfill leachate in a plot with CPCs.

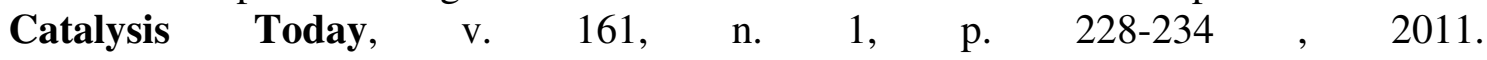
http://dx.doi.org/10.1016/j.cattod.2010.08.025

VILELA-RIBEIRO, E. B; COSTA L. S. O; LIMA-RIBEIRO M. S; SOUSA M. H. Uma abordagem normativa dos resíduos sólidos de saúde e a questão ambiental. REMEA Revista Eletrônica do Mestrado em Educação Ambiental, v. 22, n. 1, p. 168-176, 2009.

WANG, Q.; LEMLEY, A. T. Kinetic model and optimization of 2,4-D degradation by anodic Fenton treatment. Environmental Science \& Technology, v. 35, n. 15, p. 4509-4514, 2001. http://dx.doi.org/10.1021/es0109693

ZHANG, H.; CHOI, H. J.; HUANG, C. Optimization of Fenton process for the treatment fo landfill leachate. Journal of Hazardous Materials, v. 125, n. 1, p. 166-174, 2005. http://dx.doi.org/10.1016/j.jhazmat.2005.05.025 